\title{
1 Influence of genotype-temperature interaction on pollen performance
}

2

3 Hedhly, A. ${ }^{1,3}$, Hormaza, J.I. ${ }^{2} \&$ Herrero, M. ${ }^{1,3}$

4

$5{ }^{1}$ Estación Experimental de Aula Dei, CSIC. Apartado 202, 50080, Zaragoza, Spain.

$6 \quad 2$ Estación Experimental La Mayora, CSIC. 29750, Algarrobo-Costa, Málaga, Spain.

$7 \quad{ }^{3}$ Unidad de Fruticultura, CITA-DGA. Apartado 727, 50080, Zaragoza, Spain.

8 Correspondence: Afif Hedhly. Departamento de Pomología, EEAD, SCIC. Apartado 202,

9 50080, Zaragoza, Spain.

10 Tel.: +34 976 716125; Fax: +34 976 716145;

11 e-mail: ahedhly@eead.csic.es 


\section{ABSTRACT}

13 Pollen competition and selection has significant evolutionary consequences, but very little is

14 known on how they can be modulated. We have examined in cherry (Prunus avium L.) how

15 pollen performance is affected by the genotype of the pollen and by the environmental

16 conditions where it grows, namely the pistilar tissue and temperature. The different pollen

17 donor genotypes tested in this work differed in their behaviour both in vitro and in vivo and

18 this behavior was modulated depending on the female recipient were they grew. Furthermore,

19 there was a significant temperature-genotype interaction that affected the pollen tube

20 population census that succeeded to reach the base of the style. The combination of these

21 three factors, while enabling a capacity of response to variations in environmental pressures,

22 could maintain variability in pollen performance avoiding the fixation of the genes that

23 control pollen tube growth rate.

24

25 Keywords: pollen performance; pollen tube growth; Prunus avium; Rosaceae; success ratio; 26 temperature stress.

27

28 Running title: Variation in pollen performance 
30 Pollen performance, which includes pollen germination, pollen tube growth rate and pollen competition, is an important component of fertilization success in seed producing plants. Failure in pollen performance diminishes the fitness of the male parent through a reduction on its contribution to the next sporophytic generation. Differences in pollen performance could also favor reproductive isolation, by the promotion of conspecific pollen (Carney et al., 1996; Campbell et al., 2003) and, conversely, could be a way to avoid inbreeding depression promoting foreign pollen (Bateman, 1956; Hauser \& Siegismund, 2000). Both of them modulated through pollen tube growth rate and pollen tube attrition.

But modulation of pollen performance could also play a major part regulating gene flow and could have significant evolutionary consequences in terms of sexual and gametophytic selection. Sexual selection has been widely documented in animals (Birkhead \& Moller, 1998) and there are evidences that it also takes place in plants (Arnold, 1994; Morgan, 1994; Spira, 1991; Marshall, 1998; Mitchell \& Marshall, 1998). The variation in microgametophyte populations is critical for evaluating the prevalence and potential evolutionary significance of gametophytic competition (Herrera, 2002), which is a prerequisite for gametophytic selection 
between the sporophyte and the gametophyte, the two alternating generations of plants (Mascarenhas, 1989), provides a nexus between selection occurring in both generations (Hormaza \& Herrero, 1992). It has been proposed that gametophytic selection could represent a main drive in angiosperms evolution and adaptation (Mulcahy, 1979).

The prezygotic stage is emerging as a scenario for the regulation of mating (Herrero, 2003) with clear evolutive consequences both in plants and animals (Bernasconi et al., 2004). Paternity analyses are becoming a powerful tool to investigate competition and selection during the reproductive phase (Bernasconi, 2003). However the results are often difficult to interpret due to the strong influence that the maternal environment may have on embryo development and survival (Havens \& Delph, 1996) and the difficulties to separate paternal and maternal influences. In this sense, the study of pollen performance during the progamic phase may help to disentangle prezygotic and postzygotic effects.

Pollen performance is clearly affected by the genotype of the pollen (Snow \& Spira, 1991). It has been suggested that pollen competition should eventually lead to selection for rapid pollen tube growth and, hence, to the fixation of the traits controlling pollen performance (Walsh \& Charlesworth, 1992). However, several lines of evidence suggest that the genotype of the female recipient can limit the likelihood of that fixation (Mulcahy et al., 1996; Hormaza \& Herrero, 1996, 1999) and could play a clear role controlling pollen tube growth (Willson \& Burley, 1983; Stephenson \& Bertin, 1983; Herrero \& Hormaza, 1996).

On the other hand, studies in a few species have shown that environmental conditions affect pollen development (Young \& Stanton, 1990; Jóhannsson \& Stephenson, 1998) as well as pollen tube growth (Stephenson et al., 1992). If this effect is widespread in plants, it may have important evolutionary consequences. One of the most important environmental factors that could affect pollen performance is the temperature during the progamic phase. It has been shown that temperature affects pollen germination (Elgersma et al., 1989; Shivanna et al., 
1991), and pollen tube kinetics in the style (Lewis, 1942; Jefferies et al., 1982; Elgersma et al., 1989). By pollinating a female genotype with pollen from two different donor genotypes, it has been recently shown that, besides those physiological effects, temperature also affects pollen tube population dynamics and that the response to temperature during the reproductive phase is genotype-dependent (Hedhly et al., 2004). In this work, we study to which extent this may be a general phenomenon by testing in a larger number of genotypes the contribution to pollen performance of the genotype of the pollen donor, the genotype of the female recipient and temperature.

Work has been performed in cherry (Prunus avium L.) a species especially well suited for pollen competition studies for its high pollen-ovule ratio (Hormaza \& Herrero, 1996). To evaluate the effect of temperature on the pollen genotype we tested two temperature regimes, which reflect cool $\left(15^{\circ} \mathrm{C}\right)$ and hot $\left(30^{\circ} \mathrm{C}\right)$ conditions during cherry blooming. We carried out first an in vitro evaluation of pollen performance of the different genotypes. Second, we carried out an in vivo evaluation of pollen from those genotypes in one female recipient. Finally, to test the possible effect of the female recipient, we evaluated the performance of a single pollen donor in different genotypes under the two temperature regimes.

\section{MATERIALS AND METHODS}

\section{Plant material}

This work was carried out on a collection of sweet cherry (Prunus avium L.) cultivars, maintained at the SIA-DGA experimental orchards located at the 'Campus de Aula Dei' in Zaragoza, Spain. The cultivars were chosen to maximize genetic variability taking into account their compatibility relationships, geographic origin and molecular similarity (Wünsch

\& Hormaza, 2002). The genotypes studied were 'Bing' and 'Stark Hardy Giant' from USA, 
'Van’ from Canada, 'Hedelfingen' from Germany, 'Blanca de Provenza', 'Burlat' and

104 'Reverchon' from France and 'Talaguera Brillante' and 'Ambrunés' from Spain.

\section{In vitro pollen germination}

107 Pollen from the nine genotypes studied was obtained one day before anthesis from flowers

108 collected randomly from three clonally propagated trees per cultivar. Anthers were removed

109 and left to dry on a piece of paper for $24-48$ hours at room temperature. Pollen was sieved

110 through a $0.26 \mu \mathrm{m}$ mesh. Immediately after, in vitro germination was carried out at $15^{\circ} \mathrm{C}$ and

$11130^{\circ} \mathrm{C}$ in polystyrene Petri dishes $(35$ by $10 \mathrm{~mm})$ scattering pollen on a solidified germination

112 medium consisting of $0.3 \mathrm{M}$ sucrose, $0.6 \mathrm{mM}$ calcium nitrate, $1.6 \mathrm{mM}$ boric acid, and $0.8 \%$

113 (w/v) agar (Hormaza et al., 1996). Pollen germination was arrested after 24 hours at $15^{\circ} \mathrm{C}$ and

1143 hours at $30^{\circ} \mathrm{C}$, by an immediate freezing at $-20^{\circ} \mathrm{C}$. This procedure has revealed to be a

115 highly efficient method to arrest pollen germination while preserving the material for further

116 evaluation. Prior experiments evaluating pollen germination at different times showed that

117 incubation for 24 hours was sufficient to obtain the maximum pollen germination at each

118 incubation temperature. One day before observation under the microscope, the frozen Petri

119 dishes were thawed at $4^{\circ} \mathrm{C}$. Pollen was scored as germinated when the length of the pollen

120 tube exceeded the diameter of its pollen grain. For each treatment, germination was recorded

121 in five Petri dishes by counting complete fields until reaching at least 100 pollen grains in 122 each plate.

\section{In vivo pollen germination and pollen tube growth}

125 Pollination procedure

126 Two experiments were performed, one to evaluate the performance of pollen from 8 cultivars

127 on one female recipient, 'Bing', and the other to evaluate the performance of a single pollen 
128 donor, 'Bing', on 8 different female recipients. The cultivar 'Bing' was used as a male donor

129 due to its high pollen performance in vitro. To maintain uniformity we used also the same 130 genotype as the female recipient. Flowers were collected randomly from 3 trees per cultivar,

131 emasculated at balloon stage, one day before anthesis, and placed in trays with soaked florist

132 foam at room temperature in the laboratory (the average temperature was $20^{\circ} \mathrm{C}$ ). The

133 following day, 10 flowers per treatment were pollinated and, immediately, placed in the 134 controlled temperature chambers at $15^{\circ} \mathrm{C}$ and $30^{\circ} \mathrm{C}$. To compare pollen performance in vivo 135 and in vitro, pollination in vivo was performed at the same time and with the same batch of 136 pollen, collected at the same time, as the pollen used in the in vitro test. Pollination was 137 carried out by brushing gently the stigmas with a paintbrush loaded with pollen.

Determination of the stigmatic area

140 To evaluate the possible effect that the stigmatic area may have on pollen adhesion and 141 germination, the stigmatic areas of the different female genotypes were measured in the 142 experiment of 8 female recipients pollinated by one male donor. Flowers were fixed in 143 formalin: acetic acid: 70\% ethanol (1: 1: 18; FAA) (Johansen, 1940) 48 hours after 144 pollination. The day before stigmatic area determination, the pistils were rehydrated by 145 washing with distilled water 3 times, one hour each, and maintained in distilled water 146 overnight. The following day, they were hold flat on wet florist foam and observed under a 147 Wild Heerbrugg M8 binocular microscope (Wild Heerbrugg, Switzerland). Images were 148 transferred to a Quantiment 570 image analysis system (Leica, Cambridge, UK) through a 149 Cohu 8310 RGB colour camera (Cohu, San Diego, Calif., USA). 
154 Pollen grain adhesion, germination, and pollen tube growth were monitored in squash 155 preparations. For this purpose, pistils were transferred to a $5 \% \mathrm{Na}_{2} \mathrm{SO}_{4}$ solution for 4 hours, 156 autoclaved at $1.1 \mathrm{~kg} / \mathrm{cm}^{2}$ during $15 \min$ (Jefferies \& Belcher, 1974), and stained with 0.1\% 157 aniline blue in $0.03 \mathrm{M} \mathrm{K}_{3} \mathrm{PO}_{4}$ (Linskens \& Esser, 1957). Preparations were examined under 158 an Ortholux II microscope (Leitz, Wetzlar, Germany) equipped with UV epifluorescence with 159 a Band Pass 355-425 exciter filter and an LP 460 barrier filter.

160 In each flower, the numbers of adhered and germinated pollen grains were counted and the 161 percentage of pollen germination calculated. Likewise, the number of pollen tubes reaching 162 the base of the style was also counted. To express pollen tube performance in the style, the 163 success ratio was defined as [(number of pollen tubes at the base of style / number of 164 germinated pollen grains) X 1000] (Hedhly et al., 2004). combinations with the covariable were examined (heterogeneity of slopes) (Silknitter et al.,

\section{Statistical analysis}

For statistical analysis, percentage data (germination percentage and success ratio) were subjected to arcsine root square transformation. Prior to ANOVA, the data were tested for normality using the Kolmogorov-Smirnoff's test and for homogeneity of variances with the Bartlett test. The experimental design for all dependent variables was double factorial (donor/recipient, temperature) with ten repetitions. An analysis of variance by the general linear model (GLM) procedure was performed using SAS GLM v. 8 (SAS Institute Inc., Cary, N.C.), and, due to some missing values, type III sum of squares was interpreted. An analysis of covariance was carried out for the experiment of 8 female recipients pollinated by one pollen donor, taking the stigmatic area as a covariable. Different models of factor 1999) although only the model in which the covariable and its interactions could explain some 
178 variation is presented; otherwise just the ANOVA is shown. In case of significant genotype-

179 temperature interactions and for the analysis of covariance, means separation was carried out

180 using the lsmeans option. In case of no significant interaction in the analysis of variance,

181 Duncan's multiple range test was used for means separation.

182

183 RESULTS

184 In vitro pollen germination

185 The effect of two constant temperature regimes $\left(15^{\circ} \mathrm{C}\right.$ and $\left.30^{\circ} \mathrm{C}\right)$ on the in vitro pollen

186 germination of 9 sweet cherry genotypes was evaluated and expressed as the percentage of

187 germinated pollen grains (Fig. 1). The analysis of variance (Table 1) revealed a highly

188 significant effect of the main factors (temperature and pollen genotype) and a significant

189 effect of the pollen genotype-temperature interaction. While differences between genotypes at

190 both temperatures are clear, high temperature reduced pollen germination and this reduction

191 was significant for several genotypes.

192

193 Performance of different pollen donors in one female recipient

194 To evaluate to which extent these genotypic differences and the effect of temperature 195 recorded in vitro were consistent in vivo, the same batch of pollen from the 8 donors was used

196 to pollinate at the same time in vivo a single cultivar, 'Bing'. Self pollen was omitted due to

197 the self-incompatibility of this cultivar.

198 The GLM procedure (Table 2) revealed a significant effect of the two main factors, the donor

199 genotype and temperature, for all the independent variables (number of adhered pollen grains,

200 number of germinated pollen grains, percentage of germination and success ratio). However,

201 the donor genotype-temperature interaction was significant only for the number of adhered

202 pollen grains and the success ratio. 
Both the number of adhered and germinated pollen grains differed significantly among the 204 pollen donor genotypes (Table 2$)$ and these two parameters were significantly correlated $(r=$ $0.74, n=157, P<0.001)$. This may be related to the fact that small differences were recorded among the pollen donors in the percentage of pollen germination (Fig. 2a). In spite to the fact that the same pollen was placed at the same time both in the stigmas and in the germination medium, pollen performance in vivo and in vitro did not correlate. Overall, in vitro pollen germination was slightly higher than that obtained in vivo. Moreover, the ranking order of the different pollen donors between in vitro and in vivo germination was not maintained. Finally, at each temperature, larger differences in germination percentages were recorded in vitro than in vivo. In contrast to this, the number of pollen tubes that reach the base of style and, hence,

213 the success ratio, differed significantly among the male genotypes (Fig. 2b) ranging from 4.2 214 to 12.7 at $15^{\circ} \mathrm{C}$ and from 1.3 to 10.0 at $30^{\circ} \mathrm{C}$. Temperature affected significantly the adhesion of pollen grains to the stigmas (Table 2). The average number of adhered pollen grains was 677 at $15^{\circ} \mathrm{C}$ and 962 at $30^{\circ} \mathrm{C}$. However a 217 significant temperature-genotype interaction was recorded and the effect of temperature was 218 significant for some genotypes. Higher adhesion at $30^{\circ} \mathrm{C}$ resulted in a higher number of 219 germinated pollen grains, 375 at $30^{\circ} \mathrm{C}$ versus 293 at $15^{\circ} \mathrm{C}$. The increase in the number of germinated pollen grains was not proportional to adhesion since the percentage of germination was reduced at the higher temperature, and this reduction was significant for only one donor. However, this higher number of germinated pollen grains did not result in higher numbers of pollen tubes at the base of the style, and a reduction in the number of pollen tubes 224 was observed in the style at higher temperatures. Regarding the success ratio, its value was 225 lower at the higher temperature for all but one genotype and averaged 7.2 at $15^{\circ} \mathrm{C}$ versus 3.9 226 at $30^{\circ} \mathrm{C}$ (Fig. 2b). Temperature-genotype interaction was also significant for this parameter 227 indicating that the effect of temperature was genotype-dependent. 


\section{Performance of one pollen donor across different female recipients}

230 To test if the female recipient had an effect on pollen performance, pollen from the same 231 pollen donor was used to pollinate eight different female recipients. The different female 232 genotypes showed a different capacity to adhere pollen grains and there were significant 233 differences among genotypes in pollen adhesion (Table 3), which ranged from 404 to 1114. 234 The stigmatic area varied between the female recipients from $0.56 \mathrm{~mm}^{2}$ in 'B. Provenza' to $1.00 \mathrm{~mm}^{2}$ in 'Burlat'. This variation appears to contribute to the differences observed in pollen adhesion since covariance analysis revealed a significant effect of the area (Table 3 ). Different models of factor combinations with the covariable were examined and the results proved a significant effect of the covariable and its interaction on the female recipient genotypes. While the genotype of the female recipient itself explained part of the variation, the significant area-female recipient interaction implies that the magnitude of the increase of pollen adhesion with area varies with the female genotype.

As in the previous experiment, small differences were recorded in the percentage of pollen

243 germination (Fig. 3a). This resulted in a positive correlation between the number of adhered 244 and germinated pollen grains $(r=0.73, n=155, P<0.001)$ and to variable numbers of 245 germinated pollen grains that ranged from 128 to 406 , depending on the female recipient. The 246 differences in the number of germinated pollen grains at the stigma were not taken over the 247 style in spite to the fact that clear and significant differences were recorded in the number of 248 pollen tubes reaching the base of the style and, hence, in the success ratio (Fig. 3b) depending 249 on the female genotype.

250 Temperature affected significantly pollen grain adhesion (Table 3), but the different female genotypes responded differently to this effect and, while adhesion increased at $30^{\circ} \mathrm{C}$ for some genotypes, it decreased for others. Indeed the recipient-temperature interaction was highly 
significant indicating that the effect of temperature differed depending on the female

254 recipient. Temperature did no affect the number of germinating pollen grains (Table 4) and

255 affected significantly the percentage of germination in only one genotype (Fig. 3a). However,

256 temperature had a reflection on the microgametophyte population that succeeded to reach the 257 base of the style. The success ratio ranged from 0.3 to 30.4 at $15^{\circ} \mathrm{C}$ and from 0 to 10.9 at $25830^{\circ} \mathrm{C}$.

\section{DISCUSSION}

Pollen performance is affected by the pollen donor genotype

262 Pollen from the different pollen donor genotypes tested in this work behaved differently both 263 in vitro and in vivo. In vitro, significant differences were recorded in pollen performance at 264 each temperature regime among the different male genotypes. Several reasons can explain 265 these differences in pollen performance. One explanation is that the differences are 266 genetically determined (Sari-Gorla et al., 1975; Pfahler et al., 1997). An additional 267 explanation is that the differences reflect the quality of the pollen sample. Indeed, pollen 268 viability differs among species (Stone et al., 1995), genotypes of the same species (Sari-Gorla 269 et al., 1975; Bookman, 1984; Pfahler et al., 1997; Mckee \& Richards, 1998; Hormaza \& 270 Herrero, 1999; Nikkanen et al., 2000), or even among years on the same genotype (Nikkanen 271 et al., 2000). Finally, differences in pollen performance might be also due to differences in the 272 nutritive status of the developing pollen grains, affected by environmental conditions (Young 273 \& Stanton, 1990; Jóhannsson \& Stephenson, 1998) and, even inbreeding in the previous 274 sporophytic generation (Jóhansson et al., 1998).

275 However, differences in pollen germination in vitro were not maintained in vivo and the 276 percentage of germination in vivo differed little among pollen donors. Since pollen grain 277 germination and initial pollen tube growth in the stigma occur in an autotrophic way (Herrero 
\& Dickinson, 1981) and initial pollen tube growth depends on the reserves stored in the pollen

279 grain and on the pollen genotype (Jóhannsson \& Stephenson, 1998; Stephenson et al., 2003),

280 it could be expected that pollen germination in vivo could resemble in vitro behavior.

281 However, the results obtained here and in other species (Pfahler \& Linskens, 1972;

282 Stephenson \& Bertin, 1983, Hormaza \& Herrero, 1999) question the validity of the in vitro

283 evaluation as a predictor of in vivo behavior. These differences could be explained

284 considering that the stigma provides a rich germination environment equally suitable to the

285 different male genotypes.

286 Whereas the stigma somehow appears to buffer genetic differences among pollen donor 287 genotypes, pollen tube growth in the style was significantly different among male genotypes. 288 Thus, the success ratio differed significantly among pollen donors on the same female 289 recipient. Differences in pollen performance in the style had been previously recorded in other 290 species and could represent a potential for sexual selection in plants through gametophytic 291 selection (Snow \& Spira, 1991; reviewed in Hormaza \& Herrero, 1994).

\section{The female recipient modulates pollen performance}

294 While a genotypic component of pollen performance is clear, this component does not appear to perform in absolute terms, but in relation to the female recipient were the pollen tube grows. Thus, the same pollen donor showed a different performance in the different pistil

297 genotypes. These observations confirm previous indications (Herrero \& Hormaza, 1996) that 298 a genetic pollen-style interaction could be superimposed over physical and nutritional 299 differences among female genotypes. Other indications of the screening function of the style 300 come from studies of gametophytic self-incompatibility (de Nettancourt, 2001), and from 301 evidence of genetic interaction (Hormaza \& Herrero, 1996). As a result of this interaction, 302 better male-female combinations rather than better males could be occurring. 
While the path of pollen tube growth along the style appears to be specially suited to favor this interaction and selection, the stigma appears to be well devised to capture and offer support for germination to an ample variety of individuals (Herrero, 1992; Herrero \& Hormaza, 1996). Compared to in vitro, smaller differences in germination percentage were recorded in vivo, both among male genotypes on the same female recipient or among different

308 female genotypes pollinated with the same pollen, as though if the stigma sets the basis for an 309 equal opportunity starting line. This observation has been recorded in other cases, such as a 310 delay in stigma maturation (Herrero, 1983; Murdy \& Carter, 1987), a population effect where 311 a minimum number of pollen grains is required for pollen germination to occur (Hormaza \& 312 Herrero, 1994), or the change in the $\mathrm{pH}$ of the stigma to allow pollen germination 313 (Ganeshaiah \& Uma Shanker, 1988). However, all stigmas did no appear to be equally 314 successful in capturing pollen and some stigmas appear to gather over two times more pollen 315 than others. This capacity appears to be related in part to the stigmatic area offered for pollen 316 adhesion. Clear genotypic differences were recorded for this parameter and some genotypes 317 had a stigmatic surface almost twice as large as that of others. A large stigmatic area may 318 clearly contribute to enhance pollen capture and, consequently, pollen competition in the 319 style. Nevertheless, the magnitude of the increase in pollen adhesion with area varied 320 depending on the female genotype. Moreover, despite correction of variation by the 321 covariable, the genotype of the female recipient still explains some variation in pollen 322 adhesion. These results suggest that pollen adhesion may not be a merely physical process, 323 and that other additional factors could potentially be operating.

\section{Temperature affects pollen population census}

326 Temperature had an effect on pollen performance, both on pollen adhesion and germination 327 and on pollen tube growth. Furthermore, an interaction between the effect of temperature and 
genotype (donor/recipient) has been recorded. At the stigma, pollen adhesion was affected by temperature since the higher temperature increased pollen adhesion uniformly when different

330 pollen donors were used on a single female recipient. However, this response appears to be 331 mediated by the female genotype, since a differential response was obtained when testing 332 different female recipients. This differential response can be explained in terms of the stage of 333 development of the stigma at anthesis. Differences in the degree of pistil development have 334 been registered among flowers at anthesis (Rodrigo \& Herrero, 2002) and temperature is 335 known to accelerate stigma maturation and degeneration (Hedhly et al., 2003). Thus, this acceleration of maturation or degeneration by temperature could increase or decrease pollen

337 adhesion. However, the significant interaction between temperature and genotype implies that 338 the magnitude of the effect of temperature depends on the genotype.

339 Pollen germination was reduced at $30^{\circ} \mathrm{C}$ both in vitro and in vivo, although differences were 340 less conspicuous in vivo. A differential genotypic response was registered for this parameter.

341 A decrease in pollen germination with increasing temperatures has been previously recorded 342 in sweet cherry with different genotypes (Hedhly et al., 2003, 2004) and could reflect the 343 adaptation of this species to cool temperatures at blooming, since in other species optimum 344 temperatures for pollen germination appear to reflect the adaptation of the species to the 345 prevailing temperatures at their flowering time (Luza et al., 1987; Mckee \& Richards, 1998).

346 Although a significant genotype-temperature interaction for pollen adhesion and germination 347 at the stigma has been recorded, in this work genotype-temperature interaction was most 348 conspicuous for pollen tube growth in the style. In general, the higher temperature reduced the 349 number of pollen tubes that succeeded reach the base of the style, although the magnitude of 350 the effect is genotype-dependent, since some genotypes were more severely affected than 351 others. Previous work (Hedhly et al., 2004) reported a similar effect for another sweet cherry 352 cultivar, 'Sunburst'. However, pollen from 'Cristobalina', a sweet cherry cultivar adapted to 
warm conditions, was favored under high temperatures compared to pollen from 'Sunburst'.

354 The differences recorded here in relation to temperature among cultivars are not so conspicuous. This may be related to the fact that the cultivars used in this work have a narrower genetic variability for chilling requirements (900-1200 h) (Tabuenca, 1983) than the two cultivars studied by Hedhly et al. (2004). A significant different competitive ability of 358 pollen to different temperatures, paralleling species tolerance to temperature, was initially shown in Lycopersicon (Tanksley et al., 1981). Later work in other species confirmed an overlap in temperature response between the plant and its pollen (Luza et al., 1987;

361 Kristjansdottir, 1990; Hormaza \& Herrero, 1992, Mckee \& Richards, 1998) and also a 362 genotype-environment interaction (Pasonen et al., 2000, 2002), but further work is required 363 to elucidate the relationship of the response to temperature of the pollen donor plant and its 364 pollen performance. However, assuming fluctuating and heterogeneous temperature conditions, the existence of a significant temperature-genotype interaction could prevent the 366 fixation of the genes affecting pollen tube growth.

367 The effect of environmental factors during pollen development may have significant 368 evolutionary consequences on pollen performance (Delph et al., 1997). Clearly the nutritive 369 status of the plant may affect pollen performance and siring success (Young \& Stanton, 1990; 370 Lau \& Stephenson, 1993; Travers, 1999; Poulton et al., 2001) but the fact that pollen 371 performance can respond to external environmental factors, such as temperature, provides an 372 opportunity for additional selection pressure occurring during the reproductive phase. This 373 would support the idea of gametophytic selection affecting the genetic composition of the 374 next sporophytic generation (Mulcahy, 1979) and provides a basis to understand the 375 successful adaptation of flowering plants to a wide range of environmental conditions.

376 The results obtained in this work show that pollen performance is affected by the male 377 genotype, the female recipient and that there were significant temperature-male and 
temperature-female genotype interactions. These effects, while enabling a capacity of

379 response to environmental changes, could maintain variability in pollen performance avoiding

380 the fixation of the genes that control pollen tube growth rate. The maintenance of heritable

381 variation in those genes is necessary for gametophytic and sexual selection to result in 382 evolutionary changes.

\section{ACKNOWLEDGMENTS}

385 The authors thank A. Escota and R. Lopez for technical assistance, and I. Romagosa for help 386 with the statistical analyses. We thank also the two anonymous reviewers for providing 387 valuable comments that clearly improved this manuscript. A. H. was supported by an AECI, 388 SIA-DGA, and a CSIC fellowship. Financial support for this work was provided by project 389 grants INIA-RTA 01-103, CICYT AGL2003-05318-C02-01 and by the "Grupo de 390 Investigación Consolidado de Aragón”: A-02.

\section{REFERENCES}

393 Arnold, S.J. 1994. Is there any unifying concept of sexual selection that applies to both plants 394 and animals? Am. Nat. 144 Supplement: S1-S12.

395 Bateman, A.J. 1956. Cryptic self-incompatibility in the wallflower: Cheiranthus cheiri L. 396 Heredity 10: 257-261.

397 Bernasconi, G. 2003. Seed paternity in flowering plants: an evolutionary perspective. Persp. $398 \quad$ Plant Ecol. Evol. Syst. 6: 149-158.

399 Bernasconi, G., Ashman, T.-L., Birkhead, T.R., Bishop, J.D.D., Grossniklaus, U., Kubli, E., 400 Marshall, D.L., Schmid, B., Skogsmyr, I., Snook, R.R., Taylor, D., Till-Bottraud, I., Ward, 401 P.I., Zeh, D.W. \& Hellriegel, B. 2004. Evolutionary ecology of the prezygotic stage. Science 402 303: 971-975. 
Birkhead T.E. \& Moller, A.P. 1998. Sperm competition and sexual selection. Academic Press

404

405

406

407

408

409

410

411

412

413

414

415

416

417

418

419

420

421

422

423

424

425

426

427

Ltd.

Bookman, S.S. 1984. Evidence for selective fruit production in Asclepias. Evolution 38: 7286.

Campbell, D. R., Alarcón, R. \& Wu, C. A. 2003. Reproductive isolation and hybrid pollen disadvantage in Ipomopsis. J. Evol. Biol. 16: 536-540.

Carney, S.E., Hodges, S.A. \& Arnold, M.L. 1996. Effects of differential pollen-tube growth on hybridization in Louisiana irises. Evolution 50: 1871-1878.

de Nettancourt, D. 2001. Incompatibility and incongruity in wild and cultivated plants. 2n Edition, Springer.

Delph, L.F., Jóhannsson, M.H. \& Stephenson, A.G. 1997. How environmental factors affect pollen performance: ecological and evolutionary perspectives. Ecology 78: 1632-1639.

Elgersma, A., Stephenson, A.G. \& Nijs, A.P.M. 1989. Effects of genotype and temperature on pollen tube growth in perennial ryegrass (Lolium perenne L.). Sex. Plant Reprod. 2: 225-230.

Ganeshaiah, K.N. \& Uma Shaanker, R. 1988. Regulation of seed number and female incitation of mate competition by a $\mathrm{pH}$-dependent proteinaceous distribution of seed number in pods of Leucaena leucocephala (Lam.) de Wit. Oecologia 70: 568-572.

Grant, V. 1995. Sexual selection in plants: pros and cons. Proc. Natl. Acad. Sci. 92: 12471250.

Hauser, T.P. \& Siegismund, H.R. 2000. Inbreeding and outbreeding effects on pollen fitness and zygote survival in Silene nutans (Caryophyllaceae). J. Evol. Biol. 13: 446-454.

Havens, K. \& Delph, L.F. 1996. Differential seed maturation uncouples fertilization and siring success in Oenothera organensis (Onagraceae). Heredity 76: 623-632.

Hedhly, A., Hormaza, J.I. \& Herrero, M. 2003. The effect of temperature on stigmatic receptivity in sweet cherry (Prunus avium L.). Plant, Cell \& Env. 26: 1673-1680. 
Hedhly, A., Hormaza, J.I. \& Herrero, M. 2004. Effect of temperature on pollen tube kinetics and dynamics in sweet cherry, Prunus avium (Rosaceae). Am. J. Bot. 91: 558-564.

430 Herrera, C.M. 2002. Censusing natural microgametophyte populations: variable spatial 431 mosaics and extreme fine-graininess in winter-flowering Helleborus foetidus 432 (Ranunculaceae). Am. J. Bot. 89: 1570-1578.

433 Herrero, M. 1983. Factors affecting fruit set in 'Agua de Aranjuez' pear. Acta Hort. 139: 9143496.

435 Herrero, M. 1992. From pollination to fertilization in fruit trees. Plant Growth Regul. 11: 27$436 \quad 32$.

437 Herrero, M. 2003. Male female synchrony and the regulation of mating in flowering plants. $438 \quad$ Phil. Trans. R. Soc. Lond. B 358: 1019-1024.

439 Herrero, M. \& Dickinson, H.G. 1981. Pollen tube development in Petunia hibrida following 440 compatible and incompatible intraspecific matings. J. Cell Sci. 47: 365-383.

441 Herrero, M. \& Hormaza, J.I. 1996. Pistil strategies controlling pollen tube growth. Sex. Plant $442 \quad$ Reprod. 9: 343-347.

443 Hormaza, J.I. \& Herrero, M. 1992. Pollen selection. Theor. Appl. Genet. 83: 663-672.

444 Hormaza, J.I. \& Herrero, M. 1994. Gametophytic competition and selection. In: Genetic 445 control of self-incompatibility and reproductive development in flowering plants (E. G. 446 Williams, A. E. Clarke, \& R. B. Knox, eds.), pp. 372-400. Kluwer Academic Publisher, The 447 Netherlands.

448 Hormaza, J.I. \& Herrero, M. 1996. Dynamics of pollen tube growth under different 449 competition regimes. Sex. Plant Reprod. 9: 153-160.

450 Hormaza, J.I. \& Herrero, M. 1999. Pollen performance as affected by the pistilar genotype in 451 sweet cherry (Prunus avium L.). Protoplasma 208: 129-135. 
Hormaza, J.I., Pinney, K. \& Polito, V.S. 1996. Correlation in the tolerance to ozone between

453 sporophytes and male gametophytes of several fruit and nut tree species (Rosaceae). Sex. $454 \quad$ Plant Reprod. 9: 44-48.

455 Jefferies, C.J. \& Belcher, A.R. 1974. A fluorescent brightener used for pollen tube 456 identification in vivo. St. technol. 49: 199-202.

457 Jefferies, C.J., Brain, P., Stott, K.G. \& Belcher, A.R. 1982. Experimental systems and 458 mathematical model for studying temperature effects on pollen-tube growth and fertilization 459 in plum. Plant, Cell \& Env. 5: 231-236.

460 Jóhannsson, M.H. \& Stephenson, A.G. 1998. Effects of temperature during 461 microsporogenesis on pollen performance in Cucurbita pepo L. (Cucurbitaceae). Int. J. Plant 462 Sci. 159: 616-626.

463 Jóhannsson, M.H., Gates, M.J. \& Stephenson, A.G. (1998). Inbreeding depression affects 464 pollen performance in Cucurbita texana. J. Evol. Biol. 11: 579-588.

465 Johansen, D.A. 1940. Plant microtechniques. McGraw-Hill. New York.

466 Kristjansdottir, I.S. 1990. Pollen germination in vitro at low temperature in European and 467 Andean tetraploid potatoes. Theor. Appl. Genet. 80: 139-142.

468 Lau, T. C. \& Stephenson, A. G. 1993. Effects of soil nitrogen on pollen production, pollen 469 grain size, and pollen performance in Cucurbita pepo (Cucurbitaceae). Am. J. Bot. 80: 763$470 \quad 763$

471 Lewis, D. 1942. The physiology of incompatibility in plants. I. Effect of temperature. Proc. $R$. 472 Soc. London, Ser. B. Biol. Sci. 131: 13-26.

473 Linskens, H.F. \& Esser, K. 1957. Über eine spezifische Anfärbung der Pollenschläuche im 474 Griffel und die Zahl der Kallosepfropfen nach Selbstdung und Fremddung. $475 \quad$ Naturwissenschaften 44: 1-2. 
Luza, J.G., Polito, V.S. \& Weinbaum, S.A. 1987. Staminate bloom date and temperature

477

478

479

480

481

482

483

484

485

486

487

488

489

490

491

492

493

494

495

496

497

498

499

response of pollen germination and tube growth in two walnut (Juglans) species. Am. J. Bot. 74: 1898-1903.

Marshall, D.L. 1998. Pollen donor performance can be consistent across maternal plants in wild radish (Raphanus sativus, Brassicaceae): a necessary condition for the action of sexual selection. Am. J. Bot. 85, 1389-1397.

Mascarenhas, J.P. 1989. The male gametophyte of flowering plants. Plant Cell 1: 657-664.

Mckee, J. \& Richards, A. J. 1998. The effect of temperature on reproduction in five Primula species. Ann. Bot. 82: 359-374.

Mitchell, R.J. \& Marshall, D.L. 1998. Nonrandom mating and sexual selection in desert mustard: an experimental approach. Am. J. Bot. 85: 48-55.

Morgan, M.T. 1994. Models of sexual selection in hermaphrodites, especially plants. Am. Nat. 144 Supplement: S100-S125.

Mulcahy, D.L. 1979. The rise of angiosperms: A genecological factor. Science 206: 20-23.

Mulcahy, D.L., Sari-Gorla, M. \& Mulcahy, G.B. 1996. Pollen selection: past, present and future. Sex. Plant Reprod. 9: 353-356.

Murdy. W.H. \& Carter, M.E.B. 1987. Regulation of the timing of pollen germination by the pistil in Talinum mengesii (Portulacaceae). Am. J. Bot. 74: 1888-1892.

Nikkanen, T., Aronen, T., Häggman, H. \& Venäläinen, M. 2000. Variation in pollen viability among Picea abies genotypes - Potential for unequal paternal success. Theor. Appl. Genet. 101: $511-518$.

Pasonen, H-L., Käpylä, M. \& Pulkkinen, P. 2000. Effect of temperature and pollination site on pollen performance in Betula pendula Roth - evidence for genotype-environment interactions. Theor. Appl. Genet. 100: 1108-1112. 
500 Pasonen, H.-L., Pulkkinen, P. \& Kärkkäinen, K. 2002. Genotype-environment interactions in 501 pollen competitive ability in an anemophilous tree, Betula pendula Roth. Theor. Appl. Genet. 105: $465-473$.

503 Pfahler, P.L. \& Linskens, H.F. 1972. In vitro germination and pollen tube growth of maize

504 (Zea mays L.) pollen VI. Combined effect of storage and the alleles at the waxy (wx), sugary $505 \quad\left(\mathrm{su}_{1}\right)$ and shrunken $\left(\mathrm{sh}_{2}\right)$ loci. Theor. Appl. Genet. 42: 136-140.

506 Pfahler, P.L., Pereira, M.J. \& Barnett, R.D. 1997. Genetic variation of in vitro sesame pollen 507 germination and tube growth. Theor. Appl. Genet. 95: 1218-1222.

508 Poulton, J.L., Koide, R.T. \& Stephenson, A.G. 2001. Effects of mycorrhizal infection, soil 509 phosphorus availability and fruit production on the male function in two cultivars of $510 \quad$ Lycopersicon esculentum. Plant, Cell \& Env. 24: 841-849.

511 Rodrigo, J. \& Herrero M. 2002. Effects of pre-blossom temperatures on flower development and fruit set in apricot. Sci. Hort. 92: 125-135.

513 Sari-Gorla, M., Ottaviano, E. \& Faini, D. 1975. Genetic variability of gametophyte growth 514 rate in maize. Theor. Appl. Genet. 46: 289-294.

515 Shivanna, K.R., Linskens, H.F. \& Cresti, M. 1991. Response of tobacco pollen to high 516 humidity and heat stress: viability and germinability in vitro and in vivo. Sex. Plant Reprod. 4: $517 \quad 104-109$

518 Silknitter, K.O., Wisnowski, J.W. \& Montgomery, D.C. 1999. The analysis of covariance: a 519 useful technique for analysing quality improvement experiments. Qual. Reliab. Engng. Int. 520 15: $303-316$.

521 Skogsmyr, I. \& Lankinen, A. 2002. Sexual selection: an evolutionary force in plants. Biol. 522 Rev. 77: 537-562.

523 Snow, A.A. \& Spira, T. 1991. Pollen vigor and the potential for sexual selection in plants.

$524 \quad$ Nature 352: 796-797. 
Stephenson, A.G. \& Bertin, R.I. 1983. Male competition, female choice, and sexual selection

526 in plants. In: Pollination biology (L. Real, ed.), pp. 109-149. Academic Press.

527 Stephenson, A.G., Lau, T.-C., Quesada, M. \& Winsor, J.A. 1992. Factors that affect pollen 528 performance. In: Ecology and evolution of plant reproduction (R. Wyatt, ed.), pp. 119-134. 529 Chapman \& Hall, New York, USA.

530 Stephenson, A.G., Travers, S.E., Mena-Ali, J.I. \& Winsor, J.A. 2003. Pollen performance 531 before and during the autotrophic-heterotrophic transition of pollen tube growth. Phil. Trans. 532 R. Soc. Lond. B 358: 1009-1018.

533 Stone, J.L., Thomson, J.D. \& Dent-Acosta, S.J. 1995. Assessment of pollen viability in hand534 pollination experiments: a review. Am. J. Bot. 82: 1186-1197.

535 Tabuenca, M.C. 1983. Necesidades de frío invernal de variedades de cerezo. I Congreso 536 Nacional de la Sociedad Española de Ciencias Hortícolas, Valencia, Spain, 661-667.

537 Tanksley, S., Zamir, D. \& Rick, C.M. 1981. Evidence for the extensive overlap of 538 sporophytic and gametophytic gene expression in Lycopersicon esculentum. Science 213: $539 \quad 453-455$

540 Travers, S. E. 1999. A comparison of pollen performance between plants in recently burned 541 versus unburned environments. Ecology 80: 2427-2434.

542 Walsh, N.E. \& Charlesworth, D. 1992. Evolutionary interpretations of differences in pollen 543 tube growth rates. Quart. Rev. Biol. 67: 19-37.

544 Willson, M.F. 1994. Sexual selection in plants: perspective and overview. Am. Nat. 144 545 Supplement: S13-S39.

546 Willson, M.F. \& Burley, N. 1983. Mate choice in plants. Princeton University Press, 547 Princeton, N.J.

548 Wünsch, A. \& Hormaza, J.I. 2002. Molecular characterisation of sweet cherry (Prunus avium 549 L.) genotypes using peach [Prunus persica (L.) Batsch] SSR sequences. Heredity 89: 56-63. 
550 Young, H.J. \& Stanton, M.L. 1990. Influence of environmental quality on pollen competitive 551 ability in wild radish. Science 248: 1631-1633. 
554 Fig. 1 Percentage of germinated pollen grains in vitro of 8 sweet cherry genotypes in 555 controlled temperature chambers at $15^{\circ} \mathrm{C}$ and $30^{\circ} \mathrm{C}$ (mean + s.e.). Bars followed by the same 556 letter within the same temperature are not statistically different (Lsmeans option, $P<0.05)$. * 557 denotes significant differences between temperatures within the same genotype (Lsmeans 558 option, $P<0.0001)$.

560 Fig. 2 Percentage of pollen germination and success ratio of eight pollen donors at the base of 561 the style of one female recipient at constant temperatures of $15^{\circ} \mathrm{C}$ and $30^{\circ} \mathrm{C}$ (mean + s.e.).

562 Bars followed by the same letter within the same temperature are not statistically different $(P$ $563<0.05)$ * denotes significant differences between temperatures within the same genotype $(P$ $564<0.05)$. Duncan's Test for pollen germination and Lsmeans option for success ratio.

566 Fig. 3 Percentage of germination and success ratio of one pollen donor genotype at the base 567 of the style of several female recipients at constant temperatures of $15^{\circ} \mathrm{C}$ and $30^{\circ} \mathrm{C}$ (mean + 568 s.e.). Bars followed by the same letter within the same temperature are not statistically 569 different $(P<0.05)$ * denotes significant differences between temperatures within the same 570 genotype $(P<0.05)$. Duncan's Test for pollen germination and Lsmeans option for success 571 ratio. 
Fig. 1

574

575

576

577

578

579

580

581

582

583

584

585

586

587

588

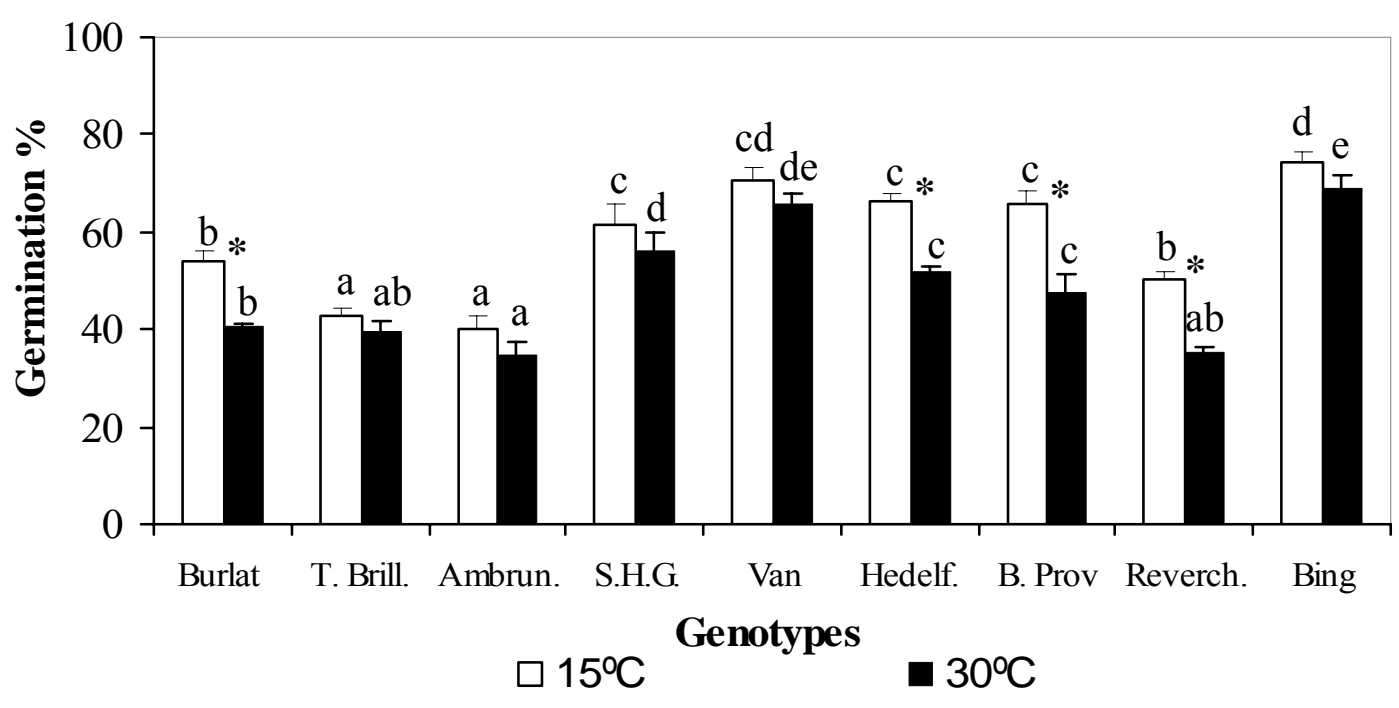

589

590

591 
Fig. 2

593

594

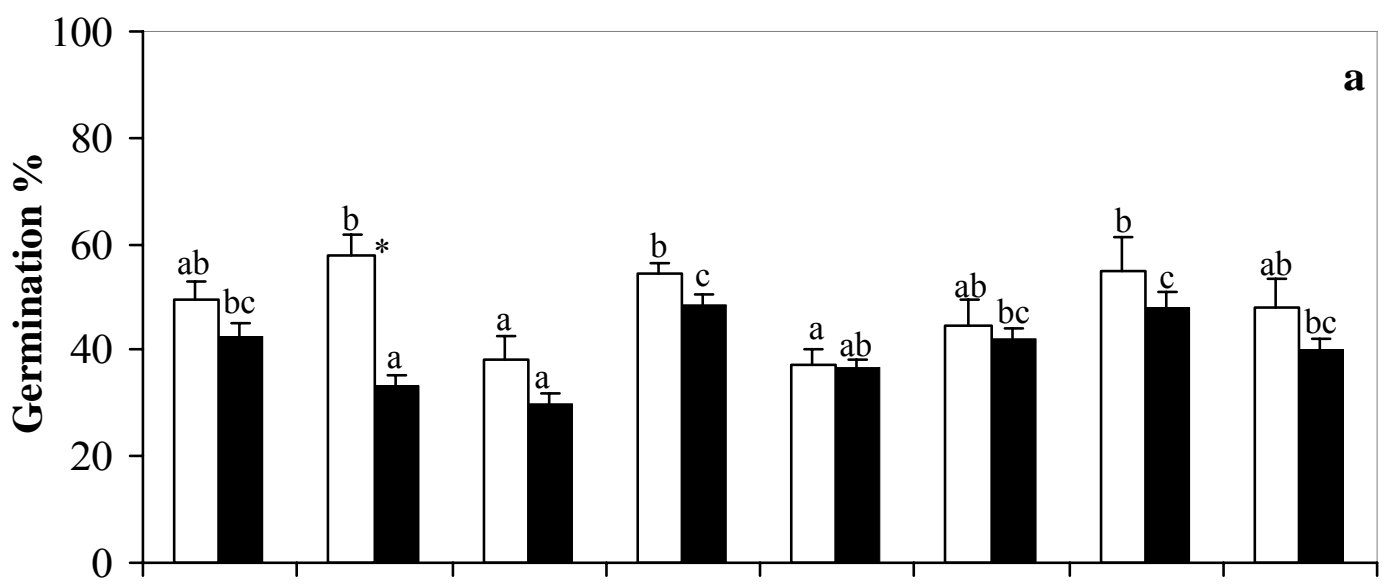

600

Burlat T. Brill. Ambrun. S.H.G. Van Hedelf. B. Prov Reverch.

601

602

603

604

605

606

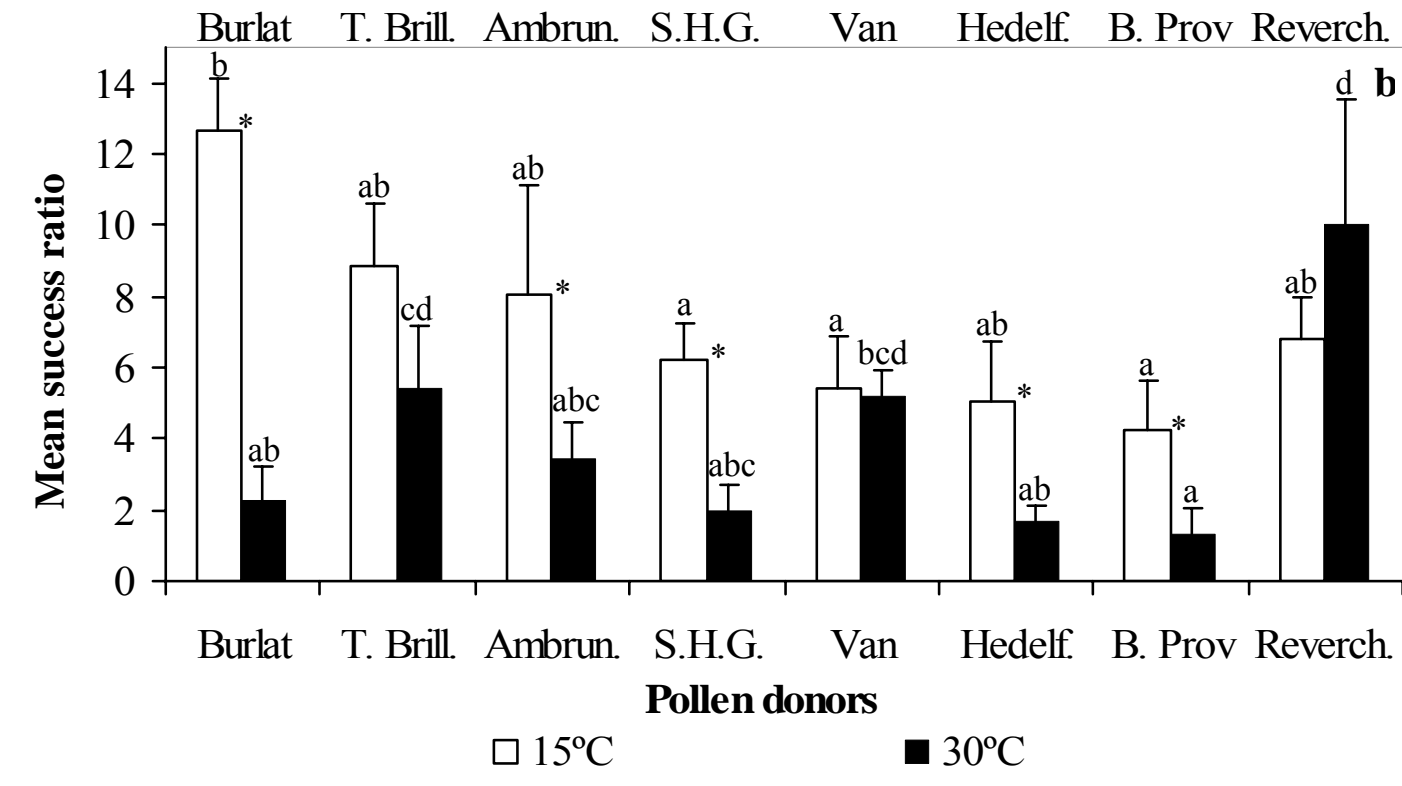

607

608

609 
Fig. 3

611

612

613

614

615

616

617

618

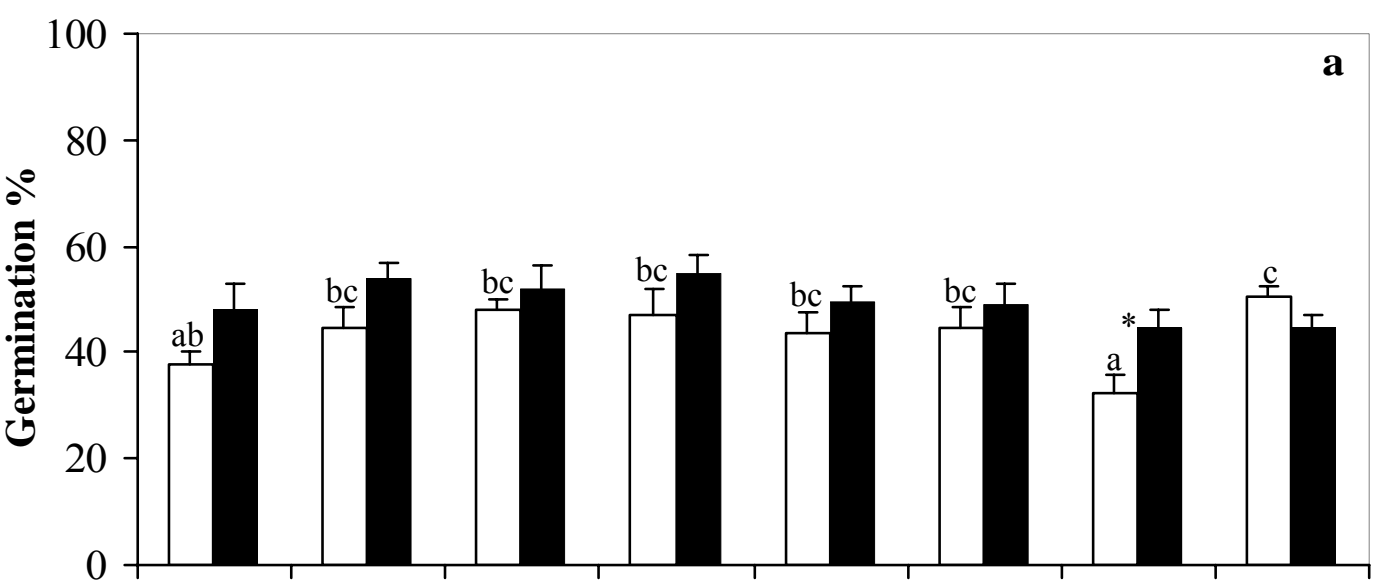

619

Burlat T. Brill. Ambrun. S.H.G. Van Hedelf. B. Prov Reverch.

620

621

622

623

624

625

626

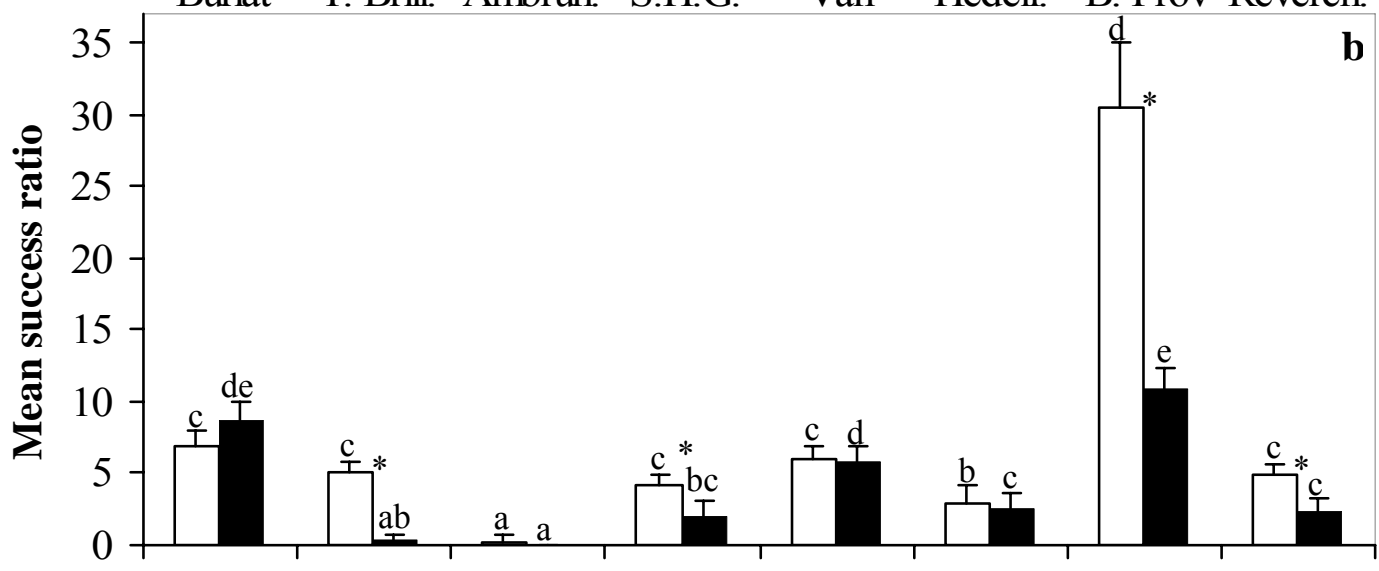

Burlat T. Brill. Ambrun. S.H.G. Van Hedelf. B. Prov Reverch.

Female recipients

627 
628 Table 1 Analysis of variance using GLM procedure for pollen germination in vitro of 9 pollen 629 genotypes.

\begin{tabular}{l|cccc}
\hline Source & DF & Mean Square & F Value & $\operatorname{Pr}>$ F \\
\hline Temperature & 1 & 680.17 & 90.56 & $<.0001$ \\
Pollen Genotype & 8 & 517.24 & 68.87 & $<.0001$ \\
Temperature*Genotype & 8 & 25.28 & 3.37 & 0.0026 \\
Error & 69 & 7.51 & & \\
\hline
\end{tabular}

630 
631 Table 2 Analysis of variance using GLM procedure for pollen adhesion ( $\left.\mathrm{N}^{\mathrm{o}} \mathrm{adh}\right)$, germination

632 ( $\mathrm{N}^{\circ}$ germ, \%Germ) and success ratio (SR) in vivo in the experiment of one female recipient

633 pollinated by eight male donors.

\begin{tabular}{|c|c|c|c|c|c|c|c|c|c|}
\hline \multirow[t]{2}{*}{ Source of variation } & \multirow[t]{2}{*}{$\mathrm{DF}$} & \multicolumn{2}{|c|}{$\mathrm{N}^{\circ}$ Adh. } & \multicolumn{2}{|c|}{$\mathrm{N}^{\circ}$ Germ. } & \multicolumn{2}{|c|}{ \%Germ. } & \multicolumn{2}{|c|}{ S.R. } \\
\hline & & MS & $\operatorname{Pr}>F$ & MS & $\operatorname{Pr}>\mathrm{F}$ & MS & $\operatorname{Pr}>\mathrm{F}$ & MS & $\operatorname{Pr}>\mathrm{F}$ \\
\hline Temperature & 1 & 2628027.29 & $<.0001$ & 186005.03 & $<.0001$ & 671.23 & 0.0003 & 1002.36 & $<.0001$ \\
\hline Donor & 7 & 811525.10 & $<.0001$ & 86622.30 & $<.0001$ & 218.82 & 0.0002 & 160.30 & 0.0034 \\
\hline Temperature*Donor & 7 & 181842.82 & 0.0089 & 15769.76 & 0.2158 & 77.20 & 0.1413 & 126.63 & 0.0167 \\
\hline Error & 141 & 63997.22 & & 11348.36 & & 48.20 & & 49.28 & \\
\hline
\end{tabular}

634 
635 Table 3 Analysis of covariance using GLM procedure, taking the area as a covariable, for the 636 number of adhered pollen grains in the experiment of eight female genotypes pollinated by 637 one pollen donor genotype.

\begin{tabular}{l|ccc}
\hline Source of Variation & DF & MS & $\operatorname{Pr}>\mathrm{F}$ \\
\hline Area & 1 & 259081.02 & 0.0061 \\
Area* Recipient & 7 & 93840.36 & 0.0093 \\
Temperature & 1 & 254633.31 & 0.0066 \\
Recipient & 7 & 96625.82 & 0.0076 \\
Temperature*Recipient & 7 & 240403.18 & $<.0001$ \\
Error & 131 & 33392.40 & \\
\hline
\end{tabular}

638 
639 Table 4 Analysis of variance using GLM procedure for pollen germination $\left(\mathrm{N}^{\circ} \mathrm{Germ}\right.$.,

$640 \%$ Germ) and success ratio (SR) in vivo in the experiment of eight female genotypes pollinated 641 by one pollen donor genotype.

\begin{tabular}{l|c|cc|cc|cc}
\hline Source & DF & \multicolumn{2}{|c|}{$\mathrm{N}^{\circ}$ Germ. } & \multicolumn{2}{|c|}{ \%Germ. } & \multicolumn{2}{|c}{ S.R. } \\
\hline & & MS & Pr $>$ F & MS & Pr $>$ F & MS & Pr $>$ F \\
Temperature & 1 & 34154.79 & 0.0524 & 488.84 & 0.0008 & 967.87 & $<.0001$ \\
Recipient & 7 & 83401.07 & $<.0001$ & 114.38 & 0.0109 & 1267.36 & $<.0001$ \\
Temperature*Recipient & 7 & 44775.46 & $<.0001$ & 55.27 & 0.2444 & 197.567 & $<.0001$ \\
Error & 139 & 8924.55 & & 41.82 & & 28.41 & \\
\hline
\end{tabular}

